\title{
Instrumental Characterization of Unmodified and HDTMA-Br Modified Kaolinite Clay: SEM-EDX, Quantachrome and TGA-DTA
}

\author{
Umar Omeiza Aroke ${ }^{1}$, Lucas Albert Jerome Hamidu ${ }^{2}$
}

\author{
${ }^{1}$ Abubakar Tafawa Balewa University \\ Dass road, P. M. B. 0248, Bauchi, 740272, Nigeria \\ ${ }^{2}$ Nigerian Building and Road Research Institute \\ 10 NBRRI Way / I.T. Igbani Street, off Awolowo Way, Jabi, Abuja, Nigeria
}

DOI: $10.22178 /$ pos.59-1

LCC Subject Category: QD1-65

Received 14.04.2020

Accepted 28.05.2020

Published online 30.06 .2020

Corresponding Author:

Umar Omeiza Aroke

zaaaroke@gmail.com

(C) 2020 The Authors. This

article is licensed under a

Creative Commons

Attribution 4.0 License

(ब) (1)
Abstract. Kaolinite clay from Alkaleri Northeast Nigeria was pre-treated and beneficiated using physical process. The treated clay of cation exchange capacity (CEC) $9.5 \mathrm{meq} / 100 \mathrm{~g}$ was modified with cationic surfactant hexadecyltrimethylammonium bromide (HDTMA-Br) with amount equivalent to and doubled the CEC. The unmodified kaolinite clay (UKC) and the resultant organokaolinite clays: monolayer modified clay (MMC) and bilayer modified clay (BMC) were characterized using the following instruments: Energy Dispersive X-ray spectrometer (EDX), Scanning Electron Microscopy (SEM), Quantachrome and Thermogravimetric-Differential Thermal Analysis (TG-DTA). EDX profile analysis shows $22.41 \%$ C, $56.17 \% 0$ \& $10.56 \%$ Al in UKC; $21.06 \%$ C, $55.49 \% 0$ \& $11.66 \% \mathrm{Al}$ in MMC and $18.98 \% \mathrm{C}, 54.59 \% 0$ \& $12.14 \% \mathrm{Al}$ in BMC respectively; with Fe and $\mathrm{K}$ found in MMC. The SEM morphology shows UKC has high porosity and large particles, while MMC and BMC showed fine particles and darker than UKC with textural non-uniformity. TGA curve shows that UKC attains equilibrium decomposition at $997.20^{\circ} \mathrm{C}$ with $15.32 \%$ weight loss, MMC $997.30^{\circ} \mathrm{C}$ with $32.67 \%$ weight loss and BMC $998.90^{\circ} \mathrm{C}$ with $37.23 \%$ weight loss. The revealed weight loss indicates water of hydration and dehydroxylation. The DTA curves shows endothermic at $510{ }^{\circ} \mathrm{C}, 250^{\circ} \mathrm{C}$ and $520^{\circ} \mathrm{C}$ for UKC, MMC and BMC respectively. The single point surface area were $11.9754 \mathrm{~m}^{2} / \mathrm{g}, 3.0132 \mathrm{~m}^{2} / \mathrm{g}$ and $3.8225 \mathrm{~m}^{2} / \mathrm{g}$ for UKC, MMC and BMC with corresponding adsorption average pore width $355.0050 \AA$, $478.6275 \AA$ and $752.8364 \AA$ respectively. Clay materials being promising minerals when modified can achieve desired surface properties for best performance in adsorption applications.

Keywords: Alkaleri-Northeast Nigeria; Characterization; Hexadecyltrimethylammonium bromide; Kaolinite clay; Quantachrome; Scanning electron microscopy / Energy dispersive X-ray spectrometry; Thermogravimetric / Differential Thermal Analysis.

\section{INTRODUCTION}

Kaolinite clay mineral in which silicon occupies all the tetrahedral sites and Aluminum two thirds of the octahedral sites (the remaining third of the sites being vacant), the composition is $\mathrm{Si}_{4}^{i v} \mathrm{Al}_{4}^{v i} \mathrm{O}_{10}(\mathrm{OH})_{8}$, where ' $i \mathrm{~V}^{\prime}$ ' is used to indicate tetrahedrally coordinated ions and ' $v i$ ' those octahedrally coordinated $[1,5]$. Kaolin clay is soft, earthy and usually white mineral produced by chemical weathering of aluminum silicate minerals like feldspar. Usually, it is colored pinkorange-red by iron oxide giving it a distinct appearance $[7,11]$, thus the resultant structural formula for one layer unit of Kaolinite clay from Alkaleri, North-Eastern Nigeria is
Na0.263K0.043Ca0.012Si4.054ivAl3.552Ti0.14 $\mathrm{Fe} 0.0733+\mathrm{Ni0} .0007 \mathrm{Zn} 0.0003 \mathrm{Cr} 0.0015 \mathrm{Mn} 0.054$ viO100H8 where the $\mathrm{Na}, \mathrm{K}$ and $\mathrm{Ca}$ are 'exchangeable', with the chemical composition $\mathrm{SiO}_{2}=53.8 \%, \quad \mathrm{Al}_{2} \mathrm{O}_{3}=40.0 \%, \quad \mathrm{TiO}_{2}=2.44 \%$, $\mathrm{Fe}_{2} \mathrm{O}_{3}=1.29 \%, \quad \mathrm{NiO}=0.011 \%, \quad \mathrm{ZnO}=0.006 \%$ $\mathrm{Cr}_{2} \mathrm{O}_{3}=0.024 \%, \quad \mathrm{MnO}=0.008 \%, \quad \mathrm{CaO}=0.15 \%$, $\mathrm{Na}_{2} \mathrm{O}=1.821 \%$ and $\mathrm{K}_{2} \mathrm{O}=0.45 \%$ [1].

Kaolinite clay mineral has a low-cation exchange capacity (CEC) ranges from 3-15 meq/100 g, the low values probably representative of pure kaolinite and the increase could depend on impurities and particle sizes [4, 8]. The CEC of Kaolinite clay from Alkaleri as determined by ammonium acetate method is $9.5 \mathrm{meq} / 100 \mathrm{~g}$ [1]. 
Kaolin as a result of its well-packed structure, are not easily broken down and its layers are not easily separated. Most sorption activity occurs along the edges and surfaces of the structure [12]. The silicates nature that makes kaolinite effective in removal (or treatment) of contaminants has to undergo purifications. The render layered silicates miscible with polymer matrices, normally hydrophilic silicate surface has to be converted to an organophilic surface to make intercalation of polymeric chain between the silicate layers, this is done by ion-exchange reaction with cationic surfactants [15].

Organoclay refers to the natural clay minerals which have their surface modified to improve their adsorption ability, capacity and affinity for oxyanion contaminants by the replacement of the natural inorganic cations with surfactants cations such as quaternary ammonium compounds (QACs) $[3,17]$. The possible application of generated organoclay is the better intercalation of polymer chains between the stack of clays, which when modified will be useful in sustaining ecosystem friendly with improved properties. This method is done by modifying the clay surface in traditional ion-exchange, and organoclay which must be treated before it can be used to make a nanocomposite. Making a composite out of untreated clay would not be very effective because most of the clay would be unable to interact with the matrix [15].

Cation exchange such as $\mathrm{Na}^{+}, \mathrm{Ca}^{2+}$ and $\mathrm{Mg}^{2+}$ may occur between the silicates layers associated with water molecules. These elements are exchangeable and their exchange reaction is very important in most of the clay application. $\mathrm{Na}^{+}$or $\mathrm{Ca}^{2+}$ or $\mathrm{Mg}^{2+}$ by quaternary ammonium cations of the forms $\left[\left(\mathrm{CH}_{3}\right)_{3} \mathrm{NR}\right]^{+}$or $\left[\left(\mathrm{CH}_{3}\right)_{2} \mathrm{NRR}^{\prime}\right]^{+}$at the exchangeable site of natural clays results in organoclay derivatives with organophilic properties that can act as a sorbent contaminant hydrocarbons $[2,9]$. The $\mathrm{R}$ and $\mathrm{R}^{\prime}$ is the alkyl or aromatic hydrocarbons.

The degree of surfactant (HDTMA ${ }^{+}$) addition is limited to the CEC of the clay being modified, where HDTMA $^{+}$replaces the charge balancing cations on the surfaces [2]. The net negative charge of the natural clay minerals is balanced by alkali metal and alkali earth metals cations such as $\mathrm{Na}^{+}, \mathrm{Ca}^{2+}$ and $\mathrm{Mg}^{2+}$ [9]. The substitution of cations is presented in Equation (1) [2], while the anions are halides such as; $\mathrm{Cl}^{-}, \mathrm{Br}^{-}, \mathrm{I}^{-}$and clay which is exchanged with the cations at surfaces.

$$
\begin{aligned}
\text { M.clay }+ \text { HDTMA } & \\
& \rightarrow \text { clayHDTMA } \\
&
\end{aligned}
$$

where $\mathrm{M}^{+}$is the metal cation such as $\mathrm{Na}^{+}, \mathrm{Ca}^{2+}$ and $\mathrm{Mg}^{2+}$.

Some common examples of monatomic/inorganic cations (metals) are alkali metal, alkaline earth metals, and transition metals while anions (halides) are chloride, bromide and iodide. Polyatomic/organic cations (metals) are ammonium, pyridinium and triethanolamine (TEA) while anions are tosyls, trifluoromethanesulfurnates and methyl sulfate. Equation (2) presents the surface action of the quaternary compounds and the clay, where clay minerals with negative charge will exchange with $\mathrm{HDTMA}^{+}$at the surface to form organoclay.

$$
\begin{aligned}
& \text { M.clay + HDTMA.X } \\
& \quad \rightarrow \text { clayHDTMA + M.X } \ldots(2)
\end{aligned}
$$

where halides $(\mathrm{X})$ are chloride $\left(\mathrm{Cl}^{-}\right)$or bromide $(\mathrm{Br})$ or iodide $\left(\mathrm{I}^{-}\right)$.

Adsorbents are usually irregular granules extruded pellets and formed spheres. The size reflects the need to pack as much surface area as possible into given volume of bed and also minimize pressure drop for flow through the bed [6]. Good adsorbents should have these qualities: large internal surface area, accessible through pores large enough to admit molecules to be adsorbed, while small pores will exclude molecules that are not desired to be adsorbed, it should not age rapidly such that it does not lose its adsorption capacity through continuous recycling and it should be mechanically strong enough to with stand bulk handling and vibration from industrial.

This research work is to instrumentally characterize unmodified and organically modified kaolinite clay from Alkaleri Local Government Area of Bauchi State, North-Eastern, Nigeria.

\section{MATERIALS AND METHODS}

The procedure used for this research work are; pretreatment and beneficiation of the raw kaolinite clay, modification of purified kaolinite clay with equivalent ratios of cationic surfactant to form organically modified kaolinite clay. 
Pretreatment and beneficiation of kaolinite clay. Kaolinite clay was obtained directly from the mining site at Alkaleri Local Government Area, Bauchi State, North-Eastern Nigeria. The clay lump was broken into particles, soaked in excess de-ionized water in a pretreated plastic container for effective dissolution and homogeneity for 48 hours. The slurry was blunged and allowed to settle for 48 hours before decantation of the excess de-ionized water and the clay residue was sun dried. This was followed by oven drying at $105^{\circ} \mathrm{C}$ for 3 hours to ensure moisture free adsorbent. The dried clay, was grinded using pestle \& mortar and passed through mesh sieve of $100 \mu \mathrm{m}$ to obtain unmodified Alkaleri kaolinite clay (raw kaolinite clay), which was characterized and stored safe in a desiccator for further usage.

Preparation of organically modified kaolinite clay. The characterized kaolinite clay from Alkaleri Local Government of Bauchi State, North-eastern Nigeria with 9.5 meq/100 g CEC [2] was modified with organic surfactant (HDTMA-Br), $99 \%$ purity and $364.45 \mathrm{~g} / \mathrm{mol}$ molecular weight, without any further treatment. The modification of kaolinite clay was carried out in two categories: the monolayer (CEC equivalent) and bilayer (twice CEC equivalent) modifications.

The synthesis of organo-kaolinite clays was carried out by weighing equivalent CEC amount of surfactant (HDTMA-Br) to produce monolayer and twice CEC to produce bilayer, dissolved in $250 \mathrm{~mL}$ of de-ionized water and stirred efficiently to ensure proper dissolution of surfactant; this was then followed by addition of known amount of unmodified kaolinite clay (UKC) with cation exchange capacity $9.5 \mathrm{meq} / 100 \mathrm{~g}$ clay to the already dissolved surfactant. The mixtures were stirred perfectly followed by addition of deionized water to make it up to $500 \mathrm{~mL}$. The mixture was then charged into a batch reactor and run at $740 \mathrm{rpm}$ for 24 hours at $25^{\circ} \mathrm{C}$ and 1 atmospheric pressure to achieve homogeneity [3]. After 24 hours of agitation in a batch reactor, the slurry was transferred into $800 \mathrm{~mL}$ beaker and allowed to settle for 24 hours, the supernatant was decanted and washed every 24 hours for four times with de-ionized water to reduce the bromide content. This was followed by drying at $25^{\circ} \mathrm{C}$ for 48 hours and oven drying for 3 hours at $104^{\circ} \mathrm{C}$, which was then ground using pestle \& mortar and passed through mesh sieve of $100 \mu \mathrm{m}$ size to produce monolayer modified or- gano-kaolinite clay (MMC) and bilayer modified organo-kaolinite clay (BMC) respectively.

Characterization of unmodified and modified kaolinite clays. The unmodified and modified kaolinite clays prepared were characterized using, scanning electron microscopy (SEM), energy dispersive X-ray spectrometer (EDX) to determine their morphologies, porosity, textural uniformity, fissures and mineralogical compositions [14]. Quantachrome analysis was carried out to determine the surface area, pore size and pore volume of the clays [2]. Thermogravimetric analyzer/differential thermal analyzer (TGA/DTA) was carried out to examine the weight loss arising from degradation of organic substances $[2,4]$.

Scanning electron microscopy/ Energy dispersive $X$-ray spectrometry. Scanning Electron Microscopy (SEM) is an electron that describes the sample by scanning a beam of electrons in a raster scan pattern. The electrons interact with the atoms that make up the sample producing signals that contain information about the sample surface topography, composition and properties - properties such as electrical conductivity. Scanning electron microscopy with energydispersed X-ray analysis (SEM/EDX) is commonly used for single particle study. It provides useful information on the morphology, elemental composition and particle density and also gives us a better insight about the origin of particles $[11,13]$. The EDX/SEM analysis was carried out using spectroscope on window SATW spectrum model. The spectrum detector was set at its maximum (X-max) to detect all elements present in the clay mineral at an elevation temperature, accelerating voltage, magnification and processing time. The adsorbent was deposited on a brass hold, followed by sputting with a thin coat of gold in a vacuum to study their morphology and surface structure. While the EDX beam were set focused into the adsorbent under study [14]. This same process was carried out for all the adsorbents to determine their mineralogical compositions and morphologies respectively.

Quantachrome analysis. Quantachrome instrument Autosorb Automated Gas Sorption System; ASAP 2020 V4.02 (V4.02 H) operating with Nitrogen as degas analyzer for adsorption analysis was used [2]. The system operated at the following conditions; thermal correction was set, warm free space was measured as well as cold free space, pressure dose and mass of adsorbent (sample). The surface area-pore, volume-pore 
size of sample clay and pore size the adsorption was measured by setting the width. These operating conditions include bath temperature, outgassing temperature, processing time, $\mathrm{P} / \mathrm{Po}$ tolerance zero, equilibrium interval time and analysis time. This same process was carried out on each adsorbent.

Thermogravimetric analysis / Differential thermal analysis. Changes in chemical or physical properties of materials as a function of temperature in a controlled atmosphere may be determined by thermal analysis [4]. This includes changes in energy, weight of materials and enablement to determine their heating patterns. The weight loss arising from the degradation of adsorbate was examined using Netsch DTA/TGA instrument thermocouple [2]. It was carried out by preconditioning the adsorbent gas flow at room temperature for 20 minutes; which was followed by heating up to $1000{ }^{\circ} \mathrm{C}$. The TGA/DTA trace was used to determine the weight percent at interval of $20{ }^{\circ} \mathrm{C} /$ minute until equilibrium value. This same process was carried out on all adsorbent to determine the temperature at which the organic content of the adsorbent degraded.

\section{RESULTS AND DISCUSSION}

Characterization of unmodified and modified kaolinite clays was carried out using SEM/EDX, Quantachrome and TGA/DTA. The results of findings are thus presented below:

Scan electron microscopy of unmodified and modified kaolinite clays. The SEM of unmodified and modified kaolinite clays was carried out for their morphologies, porosity and textural formation as shown on plate I. The SEM electrons were selected to run at $10 \mu \mathrm{m} \times 10000$ magnification to produce the images. It is always better to investigate morphologies of sorption studies of adsorbent under high magnification as it plays vital role in knowing the pressure that can allow adsorption to take place in a substance [14]. The SEM micrograph shows that UKC is highly porous, with large particle and pore sizes compared to MMC and BMC. The fissures and channels are major in UKC compared to MMC and BMC, while BMC has finer particles compared to MMC and UKC. The BMC consists of many layers and textural non-uniformity due to adequate intercalation of surface modified clay. The SEM images of unmodified kaolinite clay (UKC), monolayer modified kaolinite clay (MMC) and bilayer modi- fied kaolinite clay (BMC) are shown in Plate I (a), (b), and (c) respectively.

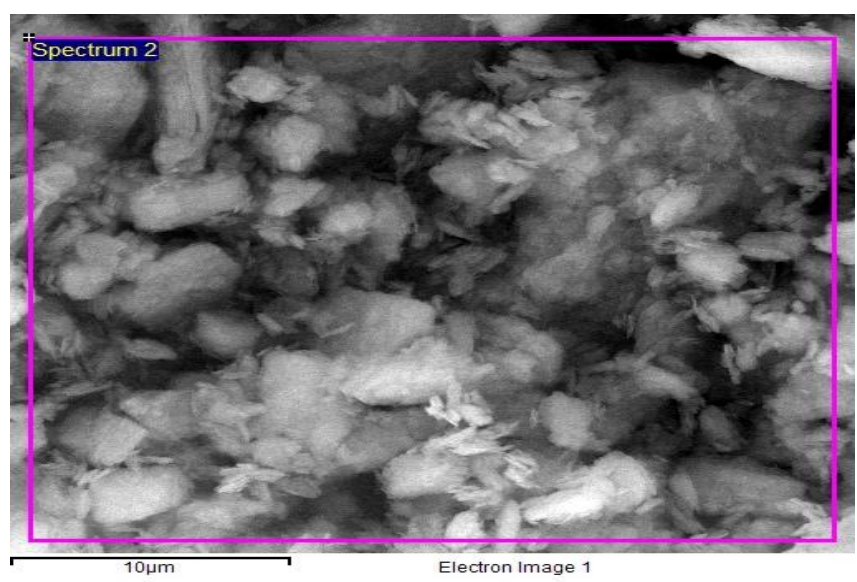

(a) Unmodified clay

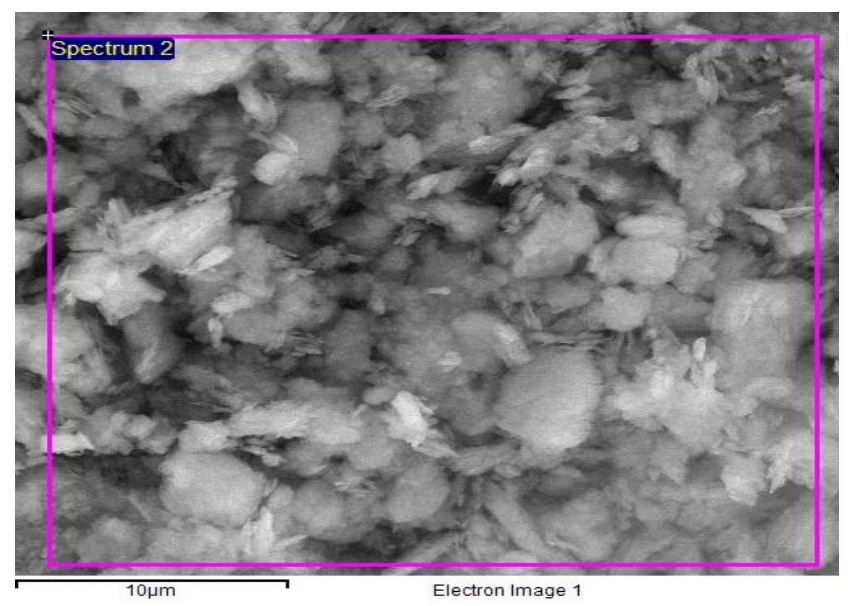

(b) Monolayer modified clay

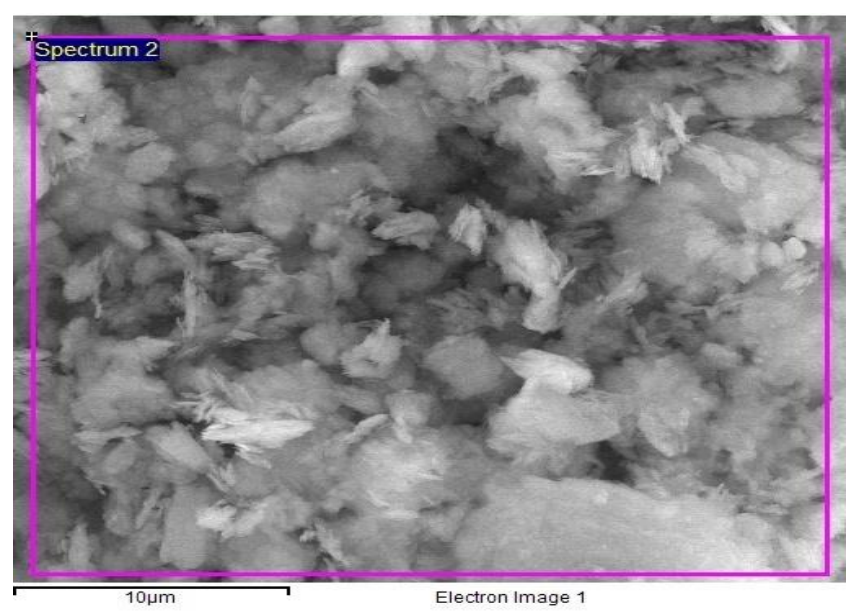

(c) Bilayer modified clay

Plate I - SEM of (a) unmodified clay, (b) monolayer modified and (c) bilayer modified clay 
Energy dispersive X-ray spectrometry of unmodified and modified kaolinite clays. The energy dispersive X-ray spectrometry was carried out on the adsorbents to determine their profiles (Figure 1) and elemental composition (Table 1).

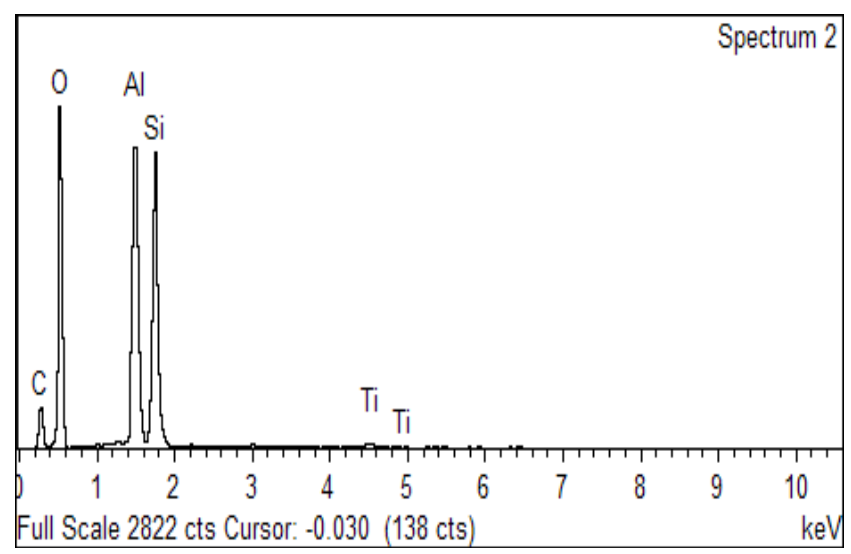

(a) Unmodified clay

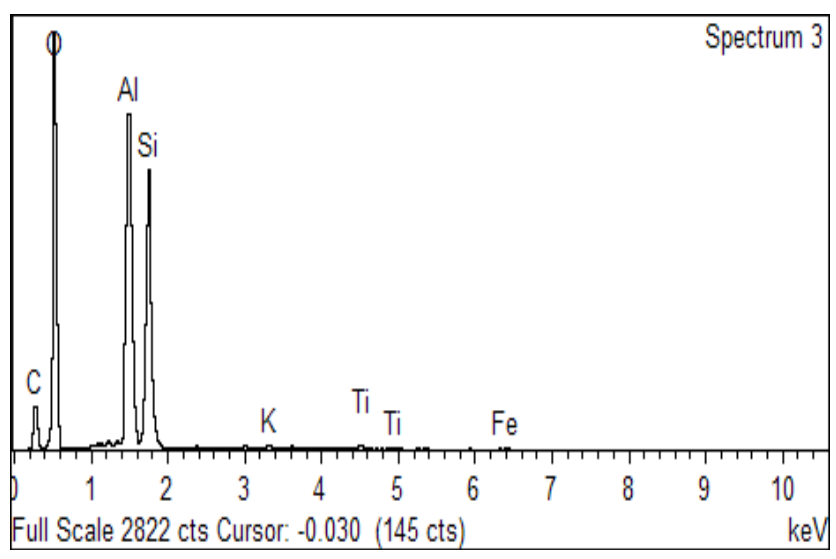

(b) Monolayer modified clay

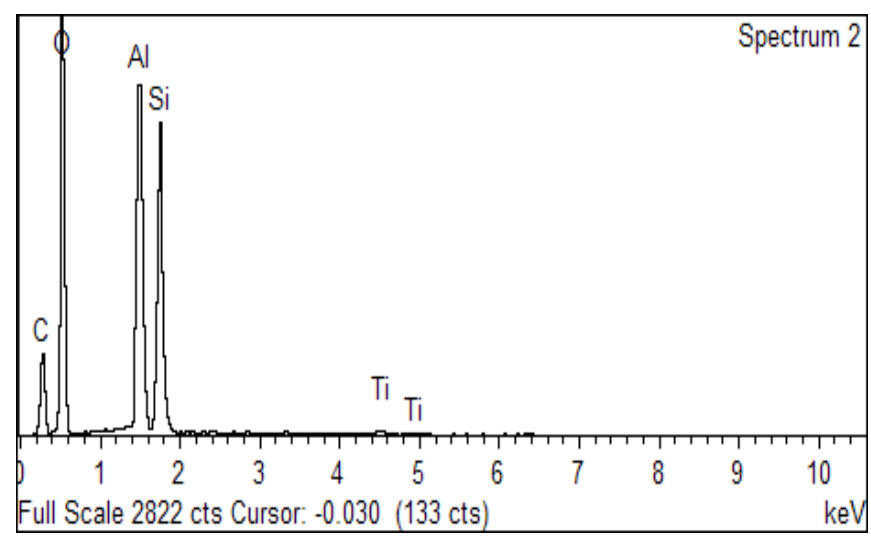

(c) Bilayer modified clay

Figure 1 - EDX profile of (a) unmodified, (b) monolayer modified and (c) bilayer modified clay
Table 1 - EDX elemental composition of unmodified and modified kaolinite clays

\begin{tabular}{|l|r|r|r|r|r|r|}
\hline \multirow{2}{*}{$\begin{array}{l}\text { Ele- } \\
\text { ment }\end{array}$} & \multicolumn{2}{|c|}{ UKC } & \multicolumn{2}{c|}{ MMC } & \multicolumn{2}{c|}{ BMC } \\
\cline { 2 - 7 } & $\begin{array}{c}\text { Weight } \\
\%\end{array}$ & $\begin{array}{c}\text { Atomic } \\
\%\end{array}$ & $\begin{array}{c}\text { Weight } \\
\%\end{array}$ & $\begin{array}{c}\text { Atomic } \\
\%\end{array}$ & $\begin{array}{c}\text { Weight } \\
\%\end{array}$ & $\begin{array}{c}\text { Atomic } \\
\%\end{array}$ \\
\hline $\mathrm{C} \mathrm{K}$ & 22.41 & 30.34 & 21.06 & 28.92 & 18.98 & 26.58 \\
\hline $\mathrm{O} \mathrm{K}$ & 56.17 & 57.09 & 55.49 & 57.21 & 54.59 & 57.39 \\
\hline $\mathrm{Al} \mathrm{K}$ & 10.56 & 6.36 & 11.66 & 7.13 & 12.14 & 7.57 \\
\hline $\mathrm{Si} \mathrm{K}$ & 10.54 & 6.10 & 11.01 & 6.47 & 13.89 & 8.32 \\
\hline $\mathrm{K} \mathrm{K}$ & 0 & 0 & 0.20 & 0.080 & 0 & 0 \\
\hline Ti K & 0.32 & 0.11 & 0.28 & 0.10 & 0.40 & 0.14 \\
\hline Fe K & 0 & 0 & 0.30 & 0.090 & 0 & 0 \\
\hline Total & 100 & 100 & 100 & 100 & 100 & 100 \\
\hline
\end{tabular}

The corresponding percentage compositions are as follows: UKC $22.41 \% \mathrm{C}, 56.17 \%$ 0, $10.56 \%$ $\mathrm{Al}, 10.54 \% \mathrm{Si}, 0.32 \% \mathrm{Ti}$; MMC $21.06 \% \mathrm{C}$, $55.49 \%$ O, $11.66 \% \mathrm{Al}, 11.01 \% \mathrm{Si}, 0.20 \% \mathrm{~K}$, $0.28 \% \mathrm{Ti}, \quad 0.30 \% \mathrm{Fe}$ and $\mathrm{BMC} 18.98 \% \mathrm{C}$, $54.59 \%$ 0, $12.14 \% \mathrm{Al}, 13.89 \% \mathrm{Si}, 0.40 \% \mathrm{Ti}$. Table 1 presents the overall view of EDX analysis elemental composition for unmodified and modified kaolinite clays. Before modification, the weight of $\mathrm{C}$ was $22.41 \%$ which reduces to $21.06 \%$ in $\mathrm{MMC}$ and $18.98 \%$ in $\mathrm{BMC}$, while $\mathrm{Al}$ and $\mathrm{Si}$ weight $\%$ increased with $\mathrm{K}$ and $\mathrm{Fe}$ found in MMC.

Quantachrome analysis of unmodified and modified kaolinite clays. Quantachrome of both unmodified and modified clays was carried out to ascertain their surface area, pore volume and pore size by surface area analyzer using Brunauer-Emmet-Teller (BET) isotherm, BarrettJoyner-Halenda (BJH) isotherm, Langmuir isotherm, t-plots, which was performed under these conditions; ground low temperature, nitrogen adsorption-desorption isotherms using an autosorb1 quantachrome instrument.

The clay surface area widely used as starting material for adsorbent varies from $10-700 \mathrm{~m}^{2} / \mathrm{g}$ [17]. The BET surface areas for UKC, MMC and BMC are $11.9754 \mathrm{~m}^{2} / \mathrm{g}, 3.0132$ and $3.8225 \mathrm{~m}^{2} / \mathrm{g}$ respectively while the $\mathrm{BJH}$ adsorption cumulative surface areas for UKC, MMC and BMC are $11.403 \mathrm{~m}^{2} / \mathrm{g}, 3.879 \mathrm{~m}^{2} / \mathrm{g}$ and $7.906 \mathrm{~m}^{2} / \mathrm{g}$ respectively. The Langmuir surface areas for UKC, MMC and BMC are $15.6659 \mathrm{~m}^{2} / \mathrm{g}, 5.6691 \mathrm{~m}^{2} / \mathrm{g}$ and $7.5577 \mathrm{~m}^{2} / \mathrm{g}$ respectively. All surface areas for UKC was found within the range of $10-700 \mathrm{~m}^{2} / \mathrm{g}$, while MMC and BMC less than $10 \mathrm{~m}^{2} / \mathrm{g}$ indicating effect of surface modifications. Total pore volume was calculated from the amount of nitrogen adsorbed at a relative pressure of $\mathrm{p} / \mathrm{p}_{\mathrm{o}}$ and while 
average pore size was calculated based on $(4 \mathrm{~V} / \mathrm{A}$ by BET) $\AA$ and $(4 \mathrm{~V} / \mathrm{A}) \AA$ as presented in Table 2 . The micro pore area, micro pore volume and ex- ternal surface area were obtained from t-plot method $[10,16]$.

Table 2 - Quantachrome analysis for unmodified and modified kaolinite clay

\begin{tabular}{|c|c|c|c|}
\hline Conditions & UKC & MMC & $\mathrm{BMC}$ \\
\hline Adsorptive analysis & $\mathrm{N}_{2}$ & $\mathrm{~N}_{2}$ & $\mathrm{~N}_{2}$ \\
\hline Analysis Bath temperature $\left({ }^{\circ} \mathrm{C}\right)$ & -195.672 & -195.718 & -195.634 \\
\hline Thermal condition & No & No & No \\
\hline Warm free space $\left(\mathrm{cm}^{3}\right)$ & 27.6944 & 28.0750 & 28.1473 \\
\hline Sample mass (g) & 0.2051 & 0.2170 & 0.3350 \\
\hline Cold free space $\left(\mathrm{cm}^{3}\right)$ & 84.2454 & 87.2358 & 84.1281 \\
\hline Equilibrium intervals (s) & 10 & 10 & 10 \\
\hline Ambient temperature $\left({ }^{\circ} \mathrm{C}\right)$ & 22.00 & 22.00 & 22.00 \\
\hline Low pressure dose $\left(\mathrm{cm}^{3} / \mathrm{g}\right.$ STP $)$ & 5.000 & 5.000 & 5.000 \\
\hline Automatic degas & Yes & Yes & yes \\
\hline \multicolumn{4}{|l|}{ Surface areas $\left(\mathrm{m}^{2} / \mathrm{g}\right)$} \\
\hline Single point surface area & 11.9754 & 3.0132 & 3.8225 \\
\hline BET surface area & 11.7037 & 3.6862 & 4.7882 \\
\hline Langmuir surface area & 15.6659 & 5.6691 & 7.5577 \\
\hline t-plot micro pore area & 7.0766 & 0 & 0 \\
\hline t-plot external surface area & 4.6271 & 4.7748 & 6.5820 \\
\hline BJH adsorption cumulative surface area & 11.403 & 3.879 & 7.906 \\
\hline BJH desorption cumulative surface area & 14.5855 & 5.0126 & 9.4495 \\
\hline \multicolumn{4}{|l|}{ Pore volumes $\left(\mathrm{cm}^{3} / \mathrm{g}\right)$} \\
\hline Single point adsorption total pore volume & 0.103872 & 0.044108 & 0.090119 \\
\hline Single point desorption total pore volume & 0.098565 & 0.055458 & 0.134071 \\
\hline t-plot micropore volume & 0.003324 & -0.000734 & -0.001178 \\
\hline BJH adsorption cumulative volume & 0.125009 & 0.067801 & 0.153947 \\
\hline BJH desorption cumulative volume & 0.124918 & 0.067588 & 0.153844 \\
\hline \multicolumn{4}{|l|}{ Pore sizes $\AA$} \\
\hline Adsorption average pore width & 355.0050 & 478.6275 & 752.8364 \\
\hline Desorption average pore width & 336.8698 & 601.7882 & 1120.0029 \\
\hline BJH adsorption average pore width & 438.513 & 699.134 & 778.933 \\
\hline BJH desorption average pore width & 342.583 & 539.342 & 651.223 \\
\hline
\end{tabular}

Thermogravimetric / Differential thermal analysis of unmodified and modified kaolinite clay. Figure 2(a), (b) and (c) presents TGA/DTA of UKC, MMC and BMC respectively which were heated between 0 to $1000^{\circ} \mathrm{C}$. The TGA curve for UKC decomposition began at $29.34{ }^{\circ} \mathrm{C}$ with a corresponding weight of $99.93092 \%$, TGA curve shows gradual decomposition at different temperatures. At $480{ }^{\circ} \mathrm{C}$ UKC exhibits decomposition of $1.97 \%$ weight loss, as heating progressed at $540{ }^{\circ} \mathrm{C}$ about $12.93 \%$ weight loss was attained and calcination continued until when the curve showed peak at $997.20^{\circ} \mathrm{C}$ with $15.32 \%$ weight loss indicating equilibrium decomposition was attained. The DTA curve began at $29.34{ }^{\circ} \mathrm{C}$ with corresponding derivative weight of $-0.19 \%$, at $100{ }^{\circ} \mathrm{C}$ the corresponding derivative weight is $0.03843 \%$, between $450{ }^{\circ} \mathrm{C}$ and $700^{\circ} \mathrm{C}$ the curves showed a sharp endothermic at $500^{\circ} \mathrm{C}$ with $-1.309 \%$ weight derivative. This showed normal process of surface water loss and dehydroxylation of clay material $[2,4]$.

The TGA curve for MMC decomposition began at $29.99{ }^{\circ} \mathrm{C}$ exhibiting $1.6 \%$ weight loss. The curve was peaked at $240{ }^{\circ} \mathrm{C}$ with $3.6 \%$ weight loss, at $270{ }^{\circ} \mathrm{C}$ the curve shows $19.6 \%$ weight loss while at $480{ }^{\circ} \mathrm{C}$ the weight loss was $21.6 \%$. Also, at $570{ }^{\circ} \mathrm{C}$ the weight loss was $29.6 \%$ until equilibrium decomposition at $997.30{ }^{\circ} \mathrm{C}$ with the corresponding weight loss of $32.67 \%$ was attained. 


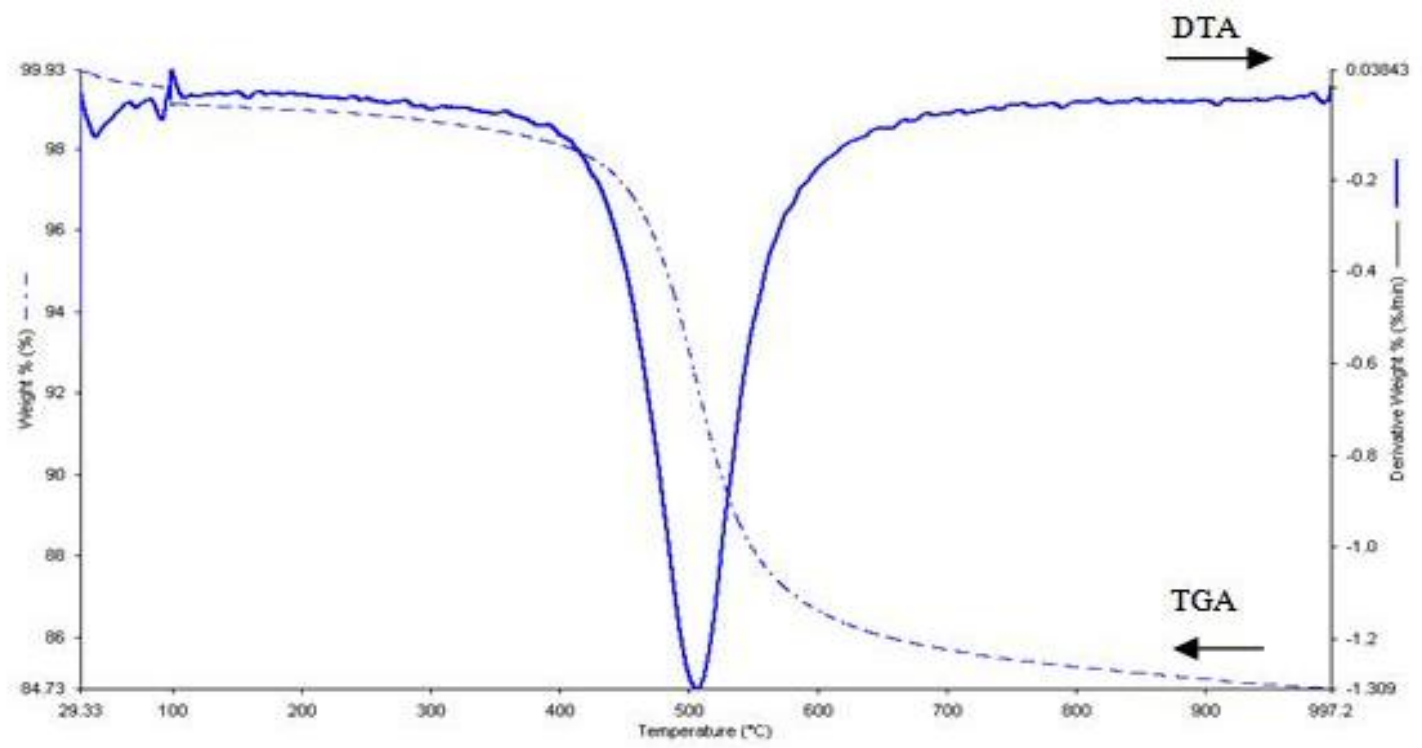

(a) Unmodified clay

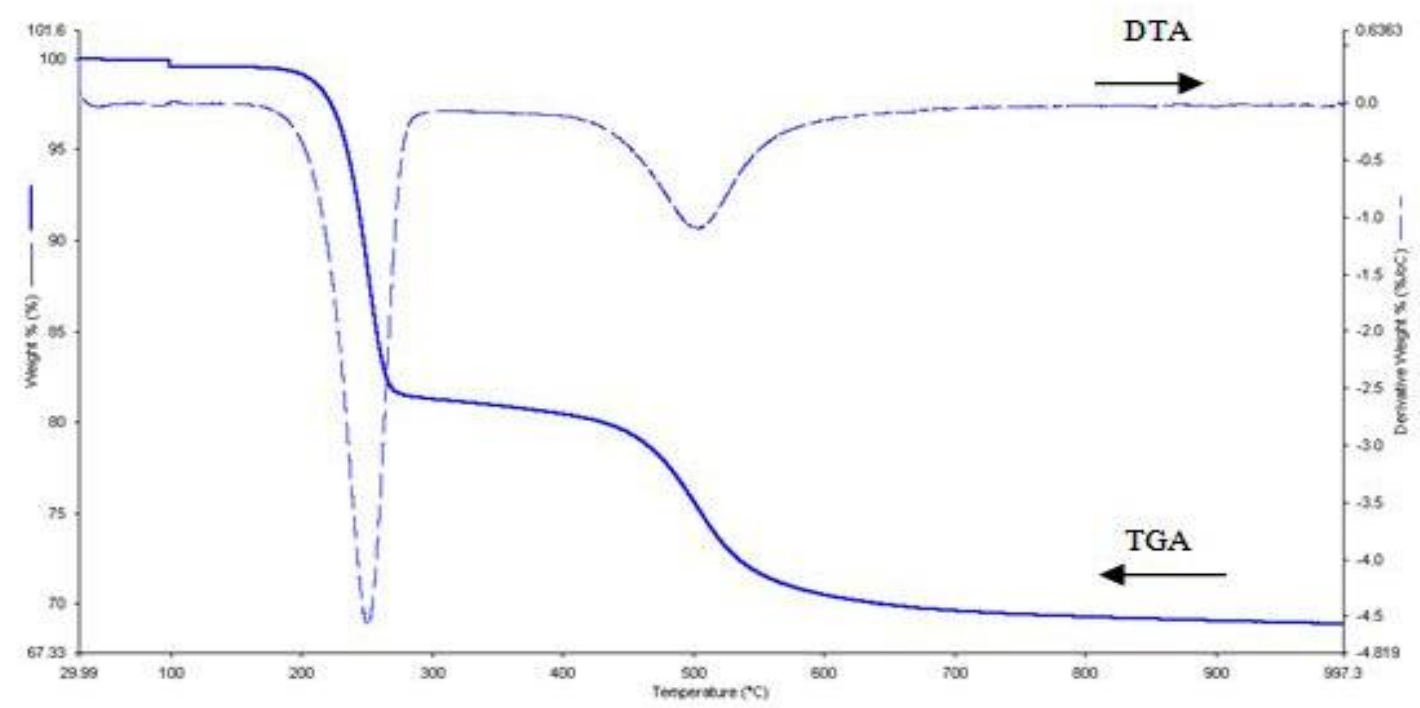

(b) Monolayer modified clay

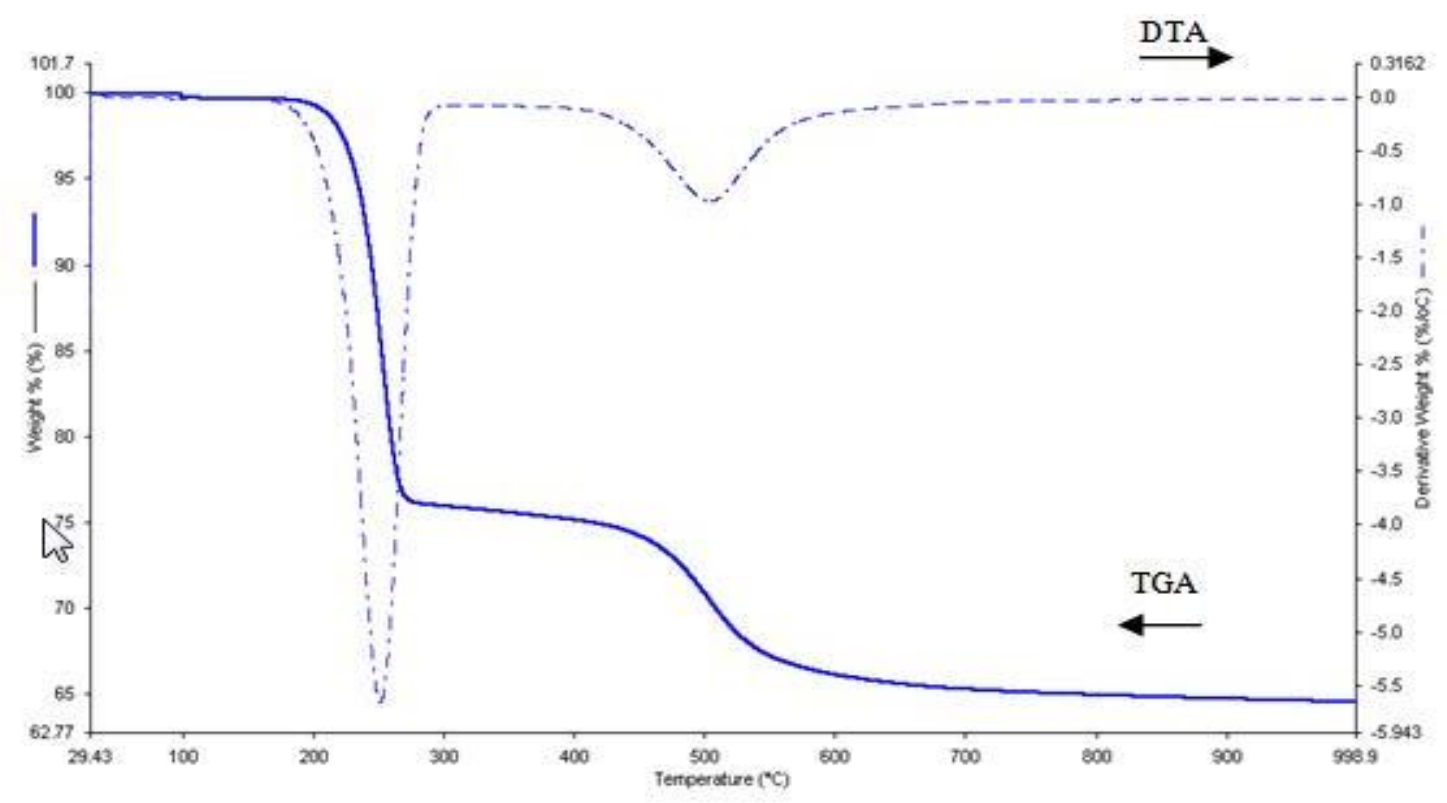

(c) Bilayer modified clay

Figure 2 - TGA/DTA of (a) unmodified clay, (b) monolayer modified clay and (c) bilayer modified clay 
DTA curve showed two endothermic decompositions, between 200 and $300{ }^{\circ} \mathrm{C}$ the curve is peaked at $250^{\circ} \mathrm{C}$ with a corresponding derivative weight $-4.5 \%$ and between 480 and $600{ }^{\circ} \mathrm{C}$ the curve is peaked at $520^{\circ} \mathrm{C}$ with a corresponding derivative weight of $-0.9 \%$. The loss is associated with surface water loss and dehydroxylation of clay materials $[2,4]$.

The TGA curve for BMC decomposition began at $29.43^{\circ} \mathrm{C}$ exhibiting $1.7 \%$ weight loss, the curve shows $26.7 \%$ weight loss at $250{ }^{\circ} \mathrm{C}$ and on further calcination the curve shows $32.50 \%$ decomposition at $570{ }^{\circ} \mathrm{C}$ until equilibrium of $998.90^{\circ} \mathrm{C}$ and $37.23 \%$ weight loss was attained. The loss is associated with surface water loss and hydration of clay materials [2, 4]. The DTA curve shows two endothermic peaks between 200 and $300{ }^{\circ} \mathrm{C}$ is peaked at $250{ }^{\circ} \mathrm{C}$ with corresponding derivative weight $-5.8 \%$ and between 400 and $600{ }^{\circ} \mathrm{C}$ the curve is peaked at $520^{\circ} \mathrm{C}$ with corresponding derivative weight $-1.0 \%$.

\section{CONCLUSION}

The SEM micrograph showed UKC with more porosity, has large particle sizes compared to MMC and BMC due to surface modification which resulted into formation of layers and textural nonuniformity. EDX show reduction in $\mathrm{C}, \mathrm{O}$ and $\mathrm{Ti}$ in UKC and increased in their percentages in both MMC and BMC. The quantachrome analysis reveal that UKC single point surface area $\left(11.9754 \mathrm{~m}^{2} / \mathrm{g}\right)$ falls within the range of clay surface area of $10-700 \mathrm{~m}^{2} / \mathrm{g}$ while MMC $\left(3.0132 \mathrm{~m}^{2} / \mathrm{g}\right)$ and BMC $\left(3.8225 \mathrm{~m}^{2} / \mathrm{g}\right)$ were less. The corresponding adsorption average pore width for UKC, MMC and BMC were $355.0050 \AA$, 478.6275 $\AA$ and $752.8364 \AA$ respectively as evidently shown by SEM micrograph for clay surface modification. The TGA of UKC, MMC and BMC were degraded at $1000{ }^{\circ} \mathrm{C}$ resulting in weight losses of $15.32 \%, 32.67 \%$ and $37.23 \%$ respectively, while the DTA had endothermic processes for UKC, MMC and BMC at $500^{\circ} \mathrm{C}$, $250{ }^{\circ} \mathrm{C}$ and $520^{\circ} \mathrm{C}$ respectively.

\section{REFERENCES}

1. Aroke, U. O, El-Nafaty, U. A., Osha, O. A. (2013). Properties and Characterization of Kaolin Clay from Alkaleri, North-Eastern Nigeria. International Journal of Emerging Technology and Advanced Engineering, 3(11), 387-392.

2. Aroke, U. O., El-Nafaty, U. A., \& Osha, O. A. (2014). Removal of Oxyanion Contaminants from Wastewater by Sorption onto HDTMA-Br Surface Modified Organo-Kaolinite Clay. International Journal of Emerging Technology and Advanced Engineering, 4(1), 475-482.

3. Aroke, U. O., Ibrahim, M., Osha, O. A., \& Yunus, M. H. (2015). Parametric Studies of Sulphate ion Sorption at different pH on HDTMA-Br Modified Kaolinite Clay. International Journal of Emerging Trends in Engineering and Development, 3(5), 250-259.

4. Bontle, M., \& Nadiye-Tabbiruka, M. S. (2007). Chemical and thermal characterization of clayey material found near Gaborone Dam. Journal of Applied Sciences and Environmental Management, 11(4), 77-80.

5. Brown, G., Newman, A. C. D., Rayner, J. H., \& Weir, A. H. (1978). The structure and chemistry of soil clay minerals. In D. J. Greenland, \& M. H. B. Hayes (Eds.), The Chemistry of Soil Constituents (pp. 29-178). Chichester: Wiley.

6. Coulson, J. M., Richardson, J. F., Backhurst, J. R., \& Harker, J. H. (1996). Chemical Engineering: Particle Technology and Separation Processes (4th ed.). N. d.: n. d.

7. Dalen, M. B., Ibrahim, A. Q., Adamu, H. M., \& Nurudeen, A. A. (2014). Effects of $\mathrm{CaCO}_{3}$ and Kaolin Filler loading on Curving Rates of Polyurethane. International Research Journal of Pure and Applied Chemistry, 4(6), 691-709.

8. El Berrichi, F. Z., \& Zen, S. (2014). Removal of Anionic Dyes from Aqueous Solutions Using Local Activated Kaolins as Adsorbers. Proceeding of the 2014 International Conference on Power Systems, Energy and Environment. Retrieved from http://www.inase.org/library/2014/interlaken/bypaper/POW/POW-27.pdf 
9. Emam, A. E (2013). Clays as Catalysts in Petroleum Refining Industry. ARPN Journal of Science and Technology, 3(4), 356-371.

10. Kaźmierczak, J., Nowicki, P., \& Pietrzak, R. (2012). Sorption properties of activated carbons obtained from corn cobs by chemical and physical activation. Adsorption, 19(2-4), 273-281. doi: 10.1007/s10450-012-9450-y

11. Li, Y., Xia, B., Zhao, Q., Liu, F., Zhang, P., Du, Q., ... Xia, Y. (2011). Removal of copper ions from aqueous solution by calcium alginate immobilized kaolin. Journal of Environmental Sciences, 23(3), 404-411. doi: 10.1016/s1001-0742(10)60442-1

12. Miranda-Trevino, J. C., \& Coles, C. A. (2003). Kaolinite properties, structure and influence of metal retention on pH. Applied Clay Science, 23(1-4), 133-139. doi: 10.1016/s0169-1317(03)00095-4

13. Pachauri, T., Singla, V., Satsangi, A., Lakhani,, A., \& Kumari, K. M. (2013). SEM-EDX Characterization of Individual Coarse Particles in Agra, India. Aerosol and Air Quality Research, 13(2), 523-536. doi: 10.4209/aaqr.2012.04.0095

14. Shakirullah, M., Ahmad, W., Ahmad, I., Ishaq, M., \& Khan, M. I. (2012). Desulphurization of liquid fuels by selective adsorption through mineral clays as adsorbents. Journal of the Chilean Chemical Society, 57(4), 1375-1380. doi: 10.4067/s0717-97072012000400009

15. Singla, P., Mehta, R., \& Upadhyay, S. N. (2012). Clay Modification by the Use of Organic Cations. Green and Sustainable Chemistry, 2(1), 21-25. doi: 10.4236/gsc.2012.21004

16. Sugumaran, P, Susan, P. V., Ravichandran, P., \& Seshadri, S. (2012). Production and Characterization of Activated Carbons from Banana Empty Fruit Bunch and Delonix regia Fruit Pod. Journal of Sustainable Energy and Environment, 3(1), 125-132 .

17. Xi, Y. (2006, May). Synthesis, Characterization and Application of Organoclays (Doctoral thesis), Queensland University of Technology. Retrieved from https://eprints.qut.edu.au/16483/1/Yunfei_Xi_Thesis.pdf 